DOI: http://dx.doi.org/10.11144/Javeriana.upsy16-1.scfe

\title{
The Structure and Content of Flow Experience Narratives in Sport: The Tale of an Elite Sportsman*
}

Estructura y contenido de las narrativas de experiencia de flow en el deporte: El relato de un deportista de élite

Received: 17 March 2015 | Accepted: 10 November 2016

\author{
Alvaro Sicilia ${ }^{\mathrm{a}}$ \\ Universidad de Almería, España \\ ORCID: http://orcid.org/0000-0001-9436-8743 \\ Juan Miguel Fernández-Balboa \\ Universidad Autónoma de Madrid, España \\ Antonio Orta \\ Universidad de Almería, España
}

a Correspondance author. E-mail: asicilia@ual.es

Para citar este artículo: Sicilia, A., Fernández-Balboa, J.M., \& Orta, A. (2017). The structure and Content of flow Experience Narratives in Sport: The Tale of an Elite Sportsman, Universitas Psychologica, 16(1), 1-13. http://dx.doi.org/10.11144/Javeriana.upsy16-1.scfe

\begin{abstract}
Through an example of structure analysis of the narrative of flow by one elite sportsman, this article attempts to shed some light on this debate in the context of understanding flow experiences as a narrative. A sportsman was invited to (a) think about flow moments; (b) describe these experiences in as much detail as possible; and (c) contextualize the experiences by delving into his life story. The recorded interviews of the participant were transcribed and subject to categorical-form and categorical-content analyses. The results show that: (a) the form and content of this participant's flow experiences were mediated by the narrative structure of his story and (b) the very story was what provided meaning to the participant's experiences of flow.
\end{abstract}

Keywords

flow; sport; narrative; structure.

\section{RESUMEN}

A través de un ejemplo de análisis de la estructura de las narrativas de flow contadas por un deportista de élite, el presente artículo intenta arrojar algo de luz sobre el debate de entender las experiencias de flow como narrativa. Un deportista fue invitado para que (a) pensara sobre momentos de flow, (b) describiera esas experiencias con tanto detalle como fuera posible, y (c) contextualizara las experiencias ahondando en su historia de vida. Las entrevistas grabadas del participante fueron transcritas y sometidas tanto a un análisis de contenido categorial como a un análisis de forma categorial. Los resultados muestran que: (a) la forma y el contenido de las experiencias de flow del participante estuvieron mediadas por la estructura narrativa de su historia y (b) la historia narrada fue la que proporcionó significado a las experiencias de flow del participante.

Palabras clave

flow; deporte; narrativa; estructura. 


\section{Statement of the problem}

Flow is an important concept in socialpsychological research and is defined as the positive state of consciousness that is experienced when one is completely involved in an intrinsically rewarding activity (Csikszentmihalyi, 1975). Initially, flow was developed in contexts unrelated to sport performance, such as leisure and work (Csikszentmihalyi, 1975; Delle Fave \& Massimini, 1988). At the end of the last century, however, sport psychologists conceived the idea that experiencing flow in competition, as an optimal mental state, could positively affect performance (Jackson, 1992; Jackson \& Marsh, 1996; McInman \& Grove, 1991). Although some studies have found a positive relationship between flow and sport performance, due to the difficulties of manipulating the subjective states of the experience, the casual consequences of flow experiences have not been established (Landhäußer \& Keller, 2012).

Despite the difficulty of establishing a universal and absolute nature of the flow experience, some researchers have sought to measure, control, and isolate its definite features and components (see Engeser, 2012). Usually, research on flow in sport is based on the nine dimensions established by Csikszentmihalyi (1990): (a) challenge-skills balance; (b) actionawareness merging; (c) clear goals; (d) unambiguous feedback; (f) concentration on the task at hand; (g) sense of control; (h) loss of self-consciousness; (i) transformation of the perception of time; and $(j)$ autotelic experience. In seeking a definition of what flow is (i.e., its dimensions), the attention has centered on the design and development of instruments and valid psychometric scales to measure these dimensions (Marsh \& Jackson, 1999). Nevertheless, according to Sparkes and Partington (2003) this psychometric interpretation of flow has its limitations and inconsistencies.

Although some authors (McInman \& Grove, 1991; Privette, 1983) have differentiated the concept of flow in sport from other types of peak moment states (i.e., peak experience and peak performance), other researchers have shown strong commonalities between these two constructs and that of flow (McInman \& Grove, 1991). Following Maslow (1968), Ravizza (1984) applied the term "peak experience" to sport arguing that, "those moments of highest happiness and fulfillment which are accompanied by loss of fears, inhibitions, and insecurities (...) as an ecstatic, involuntary moment of total integration and internal peace" (p. 453). The term "peak performance" in sport was coined by Privette (1983), who argued that, as "the prototype of superior use of human potential ... it is more efficient, creative, productive, or in some way better than habitual behavior" (p. 1362). Despite all this, empirical research has not yet fully explained the differences among the different constructs associated with optimal experiences in sport. For instance, while selfreported flow in sports such as orienteering, road cycling, and surf lifesaving has been associated with higher performance (Jackson, Thomas, Marsh, \& Smethurst, 2001); in other sports, such as marathon races, flow has been linked to a higher running motivation (Schüler \& Brunner, 2009).

On the other hand, researchers have shown differences in the descriptions of flow experiences reported by members of different groups and cultures (Jackson, 1992; Jones, Hollenhorst, Perna, \& Selin, 2000). To explain such discrepancies, Jones et al. (2000) have suggested that different activities might provoke different flow experiences, and that the differences in how individuals describe flow might be due to the fact that the questions asked and the definitions given acquire different meanings in different contexts. In this sense, Delle Fave (2009) recommends paying attention to the meaning people attribute to conscious experiences. Yet, since access to flow is only possible through self-reports, the use of language becomes a key factor. However, it must be taken into account that language itself foregrounds the difficulties most people have to verbally express their subjective experiences and this could explain why most people tend to use familiar clichés (Mitchell, 1988). 
In order to understand flow experiences, a clear definition of its characteristics, dimensions, and components becomes essential (Csikszentmihalyi, 1975, 1990; Jackson, 1992). Still, most studies of flow have conceptualized it as a mind mechanism, an approach that reflects a "pictorial" (Gergen, 1994) or "representationalist" view of language (McGannon \& Mauws, 2000) and assumes that it accurately (ontologically speaking) represents the mind states. According to McGannon and Mauws:

In this view, the words with we speak and write function by virtue of their capacity to represent what to which they refer. In simple terms, the idea is that words are merely the labels with which we refer to the things in the world (...) or out there but inside the minds of the people in which we are interested (2000, p. 150).

Although this approach has provided a strong framework to understand flow, it also has its methodological and theoretical limitations in terms of delving deeply into the interpretations the participants give to their experiences. In this regard, Sparkes and Partington (2003) warn that little attention has been paid to the origins and the context within which certain meaning inconsistencies appear. Hence, arguing that language also mediates flow experiences, these researchers call for an analysis of narrative on flow so to reveal the ways in which participants use language to construct their experiences, instead of reflecting them.

\section{Flow experience as narrative}

In this study, rather than assuming that descriptions of flow reflect concrete mental states, the authors assume that flow experience and their descriptions are not limited to the linear communicative relationship between the narrator and the listener and, hence, they may acquire certain meaning due to the way in which language is use in social interactions. Therefore, a particular tale of flow may derive a particular meaning depending on who is talking, the circumstances in which it is tell, and to whom it is being narrated. As such, the conception of flow used here follows a pragmatic spark ontological approach (Gergen, 1994) that sees this type of experiences as mediated by language and developed through a process of cultural construction and transformation called narrative (Riessman, 2008).

By narrative we refer to (a) the experience expressed as a story and (b) the research focus seeking patterns and ways of constructing meaning from personal temporal actions through the description and analysis of biographical data. In other words, narrative includes both the investigated phenomenon and the research method itself. However, not all texts or stories can be understood as narrative. Smith and Sparkes (2009) explain that narrative is a complex genre that routinely contains a beginning point, a cast of characters, and the capacity to connect events that unfold sequentially in time and space to provide an overarching explanation or consequence. In the same vein, several authors talk about a narrative tale having its own articulation within a particular structure, i.e., "emplotment" or "plotting," that, besides having a clear beginning, some interacting characters, and an explanation of final sequence, confer meaning to a sequence of events within a particular space (Gergen, 1994; Riessman, 2008). Granted, not all descriptions or texts have a narrative structure (Riessman, 1993), nor these are pristinely there for the researcher to easily find and interpret them. This is why a keen conceptual and methodological approach is needed to identify, re-create, and interpret the narratives contained in individual and group tales (Riessman, 2008; Brett, Smith, \& Sparkes, 2009).

Also, although narrative in elite sport has been thoroughly studied by social psychologists (Carless \& Douglas, 2009, 2013a, 2013b; Douglas \& Carless, 2009; Sparkes \& Smith, 2003), few researchers have undertaken empirical research in terms of flow experiences. A worthy exception being Sparkes and Partington (2003), who, in their study of a white water canoeing club context, found that talking about flow entails a relational performance shaped by 
a number of narrative resources and auspices that, in turn, may differ depending on the gender of the narrator. Moreover, centering on how flow experiences were told, Sparkes and Partington (2003) showed that the coherence of the tales was not an inherent characteristic to the experience itself; instead, it was constructed within the very act of narration and derived from the available structures, relations, and meanings in that particular context. From this perspective, flow experiences might be perceive as the narratives embedded within autobiographical stories that, in turn, attribute meaning to, and feed the storytellers themselves. This reveals that the tales of flow in sport may not necessarily be faithful reflections of people's experiences. Therefore, studying flow experiences from a narrative perspective may lead to a greater understanding of the role such experiences play in the lives of athletes.

According to Riesman (1993):

like weight bearing walls, personal narratives depend on certain structures to hold them together. Stories told in conversation share common parameters, although they may be put together in contrasting ways and, as a result, point to different interpretations. Events become meaningful because of their placement in a narrative. $(1993$, p. 18)

In this sense, while narrating their experiences of flow, sportspersons use and combine certain narrative structural elements to construct their tale, pointing, by the way, to the terms in which they wish to be understood. Coffey and Atkinson (1996) suggest that researchers may consider not only how sportspeople manage and tell their flow experiences, but also why they remember particular events while dismissing others, and why they express these events in the ways they do. Reasonably, these considerations should provide researchers with additional meanings and perspectives (Smith \& Sparkes, 2009).

\section{Purpose of the study}

In view of all that has been said until now, this study extends the application of narrative research so as to illustrate more deeply how sportspeople attribute meaning to their flow experiences through their constructed narratives. As such, it analyzes how the structure (i.e., the way of telling a story) can help understand the content (i.e., what is told). Furthermore, in order to understand the role narrative structure plays, not only in relation to the meanings of the stories told, but also as a shaping factor in the flow contained therein (Labov \& Waletzky, 1967; Riessman, 2008), this study analyzes the narrative structure so as to identify how an elite sportsman (a) tells his stories; (b) shapes the events that he is narrating; (c) contextualizes his episodes of flow; and (d) inserts these episodes into his autobiography.

Although what is presented here stems from a larger study that analyzed the narrative structure of flow from three elite sportsmen in diverse sports (citation omitted to guard anonymity in the evaluation process), given the space limitations of this article, presenting the three cases would hamper the extent to which we can demonstrate the achievement of the purposes of the study and dilute the content of the results. Therefore, we have chosen to include an in-depth description of the process of only one of the participants. Moreover, this selective decision is based on a representational strategy commonly utilized in papers publishing narrative research (Carless \& Douglas, 2013b; Smith \& Sparkes, 2011; Sparkes \& Smith, 2003) so as to communicate the results in different and potentially enlightening ways. As such, we suggest that the example that we have chosen suffices to accomplish the purposes of our study: to show (a) the non-universal character of flow and (b) the dynamic process through which flow experiences acquire meaning in relation to the context wherein these narratives are produced. In other words, given both the purposes of the study and the similar characteristics of the participants, what is relevant here, more than showing that this process happens across all them, it to show that it does happen and shed some light on the process through which this happens. Hence, it is reasonable to think that this one case suffices to provide evidence regarding 
the fact that the very structure of a narrative tale of flow may affect the meaning attributed in these experiences.

\section{Method}

\section{Participant}

Kartión (pseudonym) used to be an elite sportsman in track \& field, and had represented his country (Spain) at international events. His sporting success gave him a certain social notoriety and turned him into a local hero at a time when Spain was riddled with post-Civil War hardships. Kartión describes how, at that time, as his victories were published in the local press, masses of people would go greet him at the train station upon his return from international events. Presently, in his mid-eighties, he still coaches some athletes and remains vocationally connected to his sport.

Kartión was very suited for this study because, besides being willing and easily accessible and having a narrative competence (important factors that facilitate this type of biographical research), he has had a life-long career immersed in athletics implying a wealth of experiences associating flow in high-performance competition.

\section{Procedure}

After being informed of the conditions of his participation (the purposes of the study, the length and frequency of the interviews, the use of pseudonyms, his right to withdraw from the study, etc.), and having provided his informed consent, Kartión was interviewed three times, for two to three hours in each case, at his own home. The interviews were semistructured around several central themes so as to evoke narratives of flow experiences. Following Jackson and Csikszentmihalyi's script (1999, p. $8)$, the interviewer, a former sports coach and an acquaintance of the participant, encouraged Kartión to provide accurate examples of the flow experiences during his athletic career by asking him to recall specific instances in which he was totally absorbed in what he was doing, felt strong and positive, and did not worry about himself or a possible defeat. Kartión was also urged to use as many of his senses as possible to recall these events. Also, to stimulate his memory and the recounting of his flow experiences, basic questions were occasionally asked, including (but not limited to), how the experience began, when and where it happened, who was involved besides him, and what happened to induce such a state of flow.

All the interviews were undertaken, recorded, and later transcribed for later analysis by the lead researcher in order to avoid inter-interviewer variability in the framing of questions and the handling of the interview.

\section{Data analysis}

To identify the dimensions of flow from the recorded stories, the interview transcripts were initially subjected to a categorical-content analysis (Lieblich, Tuval-Mashiach, \& Zilber, 1998; Polkinghorne, 1995; Riessman, 2008; Sparkes \& Partington, 2003). This approach focused on the narratives that occurred in different parts of the stories. The process entailed moving from the narratives to their common elements. According to Polkinghorne (1995), this can be achieved in two ways: either by inductively observing the themes that emerged and the concepts that were developed in the stories or, on the other hand, by deductively using concepts derived from the already established theory so as to observe the reflection of these concepts within the data. This study applied the second method by using the nine dimensions posited by Csikszentmihalyi (1990), as well as Jackson and Csikszentmihalyi (1999). In the first analysis stage, our intention was to show that the stories contained distinctive elements of flow and not to examine the similarities and differences between the accounts of flow.

Once the dimensions of flow in Kartion's narratives were identified, we conducted a 
categorical-form analysis (Lieblich et al., 1998). To this end, and in accordance with Riessman (1993), we began analyzing the narrative structure in order to determine how each story was organized (i.e., why the participant developed his stories in particular and personal ways). As such, the focus shifted not only from what was told (i.e., the content included by the participant as flow) to the telling process (i.e., how he structured their stories), but also from the experience of the participant to the narrative itself. This procedure prevented "the tendency to read a narrative simply for content and the equally dangerous tendency to read it as evidence for a prior theory" (Riessman, 1993, p. 61).

The categorical-form analysis was conducted following the evaluative model of Labov and Waletsky (1967), in the way utilized by Riessman $(1993,2008)$. This model was chosen because, as Labov and Waletsky (1967) point out, narratives have formal and structural properties that are related to their social functions. Moreover, these structural properties exhibit recurring patterns that can be identified and used to interpret each narrative segment (Coffey \& Atkinson, 1996). Furthermore, the evaluative element of this model, by focusing on the perspective each participant provides to his or her tales, offers the valuation he or she places on these experiences. In this way, researchers can do several things: (a) access the meaning that the story may have for the narrator; (b) see the underlying structure upon which meaning is constructed; and (c) discern those narrative elements that may be related with the social uses and functions at particular times and in concrete contexts.

In our case, the analysis model basically consisted of identifying the narrative elements according to a temporal sequence: (a) a narrative summary (summary); (b) a description of the time, the place, the situation, and the participant within the situation (orientation); (c) a description of the sequence of actions, changes, crises, and the problems that arise (complication); (d) the narrator's comments on the action (evaluation); (e) the resolution of the narrated situation (resolution); and (f) the end of the narrative and return to the present (coda).
The reiteration of the narrative elements used by the participant suggests that personal flow experience narratives can be structured according to certain socially-shared conventions that, as noted by Mendoza (2004), render the stories more comprehensible in the socio-cultural context in which they are produced. Thus, using the narrative elements socio-culturally available, the stories become more credible within those contexts.

\section{Results and discussion}

The results are presented in two sections. First, we introduce those concerning the structure in Kartión's flow experience narratives and, next, we comment on the narrative structure as a determinant factor of flow experience. Some discussion accompanies each section.

\section{The structure in flow experience narratives}

Regarding the structure of Kartión's flow experience narratives, while recounting a moment in which he was completely absorbed in his activity and felt strong and positive, oddly enough, he began to tell a seemingly disjointed and chaotic story regarding his unsuccessful attempts to achieve a champion's glory:

No. I could not experience [flow] because I did not have the opportunity (...) because I never managed to get good training. I had a just few months of groundwork [which were immediately] followed by specific training [summary ${ }^{1}$ ]. The training consisted of running in the morning (...) and the afternoon. In the morning, I would go down to the river and come back from the river along the beach. After a brief pause, I'd go again. In the afternoon, I'd run up to the castle. I worked out and did some gymnastics and I would think. Always running long distances is [not good] because, then, when I have to run fast, the heart suffers more because it isn't used to it. I should run faster, even if I do different heats and I went to the Spanish University Championships with this 
training. I became a college champion without good training. Then I run in Barcelona, with Piferrer, Adarraga, [and others], and I beat them all, even with those [rudimentary] workouts I had done [orientation and complication].

So I used to compete a little unsettled. I was unsure of whether or not I would win. [I was] always nervous [evaluation]. No, I did not have the confidence to say that [I would win] [result].

Eventually, I did get enough confidence. So yeah, finally that time came when I ran in Tolosa [Spain] (...) and I beat everyone. So I stopped being worried [summary]. I remember one time, having finished my workout, I was running to back the locker room and thinking, "No one in the world can beat me." I saw myself running and said, "No one can run like me" (...). I was also very strong in the Spanish Championship organized by the Frente de Juventudes ${ }^{2}$ in Tolosa. (...) I was unbeatable. All those races (...). It was impossible for anyone to beat me. I definitely remember running in Tolosa [orientation]. I went there knowing that I was going to win. I broke the Spanish record, running the 600 meters in 1 minute, 25 seconds, and 9 hundredths. It was raining and the ground was very muddy, but I could not have run any faster. I knew that I was going to win. I was confident [complication].

That was where I got epididymitis [orientation]. You see, when the Italians saw me running they said, "Champion of Europe! Undisputed!" And then, in the functional tests that I did in Italy, I came out the best. People were stunned and, you know, we trained daily and worked hard, even on Sundays (...) to perform well [and] to justify the records they [the coaches and federative officials] were setting for us. [Starting] on Monday, we trained until Saturday, and on Sunday [we had] to set new records. The workouts were of 1000 meter heats. Do you know what the warm-up was for that? A lap on our tiptoes! I did not even know what tiptoeing was! The warm-ups-I would sit there eating a banana to get my strength up, hoping to not get tired during the heat. We run heats without any warm up [complication].

(...) And that's where my athletic career ended. I do not like talking about it because I consider it a failure. [summary] (...) My life was ruined by hepatitis, epididymitis, and a knee injury (...). The world fell apart around me. I was the best in the world, and this is what happened to me. It was a devastating blow (...) [evaluation and result]. You see, the year after I got sick with tuberculosis, they took me in so I could recover. I was there, being fed, getting my shots and everything else (...) and the idiots would push me. A doctor told me, "There's going to be an attempt to break the Spanish national record for the $4 \times 800$ meters, and we'd like to give you the chance to defend it because you're the national record holder." What idiots! [orientation and complication] They did not have a runner who could run it in less than two minutes, and they expected me to do it. Idiots! (...) I was foolish, though, like a little kid. I did it in 2 minutes, 4 seconds! Can you believe it? Without training! [evaluation] They led me to that. We trained all day, every day, including Sundays. There was no rest! [result and coda] (March 18, 2009).

As one can see, in Kartión's story there are several orientations and complications, with plots that are developed across several scenarios. The first scenario corresponds with an initial summary and describes the training conditions of the athlete, whereas the second scenario refers to significant moments of his athletic life in which, apparently, he experienced flow. The first plot contains an evaluation and a result, i.e., he competed under stress and, consequently, could not enjoy the moment. Then, instead of ending with a coda, the story takes on two new plots: (a) his athletic successes in Tolosa (Spain), and (b) the bitter experiences prior to his retirement. These plots, with their respective orientations and complications, do end with a lamenting coda (i.e., "They led me to that. We trained all day, every day, including Sundays. There was no rest!"). He did all this in order to justify the beginning summary regarding his tragic athletic career ending.

Kartión inserted his tale of flow, or lack thereof, within a performance narrative, a dominant type of narrative in elite sports culture (Carless \& Douglas, 2009; Douglas \& Carless, 2009; Sparkes \& Smith, 2003). This makes sense, given that a story of "single-minded dedication to sport performance" (i.e., oriented to winning results) tends to be linked to the storyteller's 
mental wellbeing, identity, and self-worth. Yet, it has its drawbacks, since such an orientation is taken at the expense of other worthwhile possibilities of life and self (Carless \& Douglas, 2009). Kartión's narrative is a clear example of how other interpretations or meanings of flow, that otherwise could have emerged in other contexts, are dismissed.

Moreover, Kartión's tale, containing some narrative elements of flow experiences that are key to the tale, reveals a history of unsuccessful self-improvement and a titanic struggle against his body and the incompetence of his coaches and sport physicians. Concerning the question about his peak moments in sport, he weaves a story that seeks to justify why his glorious moments were so ephemeral. He does so using a narrative structure that, when inserting Labov and Waletzky's (1967) evaluative elements, appears to be disjointed. Yet, oddly enough, this apparently chaotic narrative structure provides the story with an internal consistency and legitimacy within the communicative context in which it was produced. In other words, this particular form of narration imbues the story with such a teleological orientation that all the narrative elements (e.g., the actors, actions, settings, and plots) end up serving a single purpose: to explain the value, somewhat heroic, of the narrator. Thus, Kartión's flow experiences are not only described, but also voluntarily (or instinctively) framed within a narrative context that provides internal coherence to the story. In other words, Kartion's tale has an internal logic and is developed using a time-line plot, with a beginning, a rising action, and an end. This style is consistent with the argument given by Riessman (1993) that the answers people provide during research interviews tend to be coherently structured because this form of speech is well known and commonly used in everyday interactions. A story is an obvious way to relate important experiences and events (Coffey \& Atkinson, 1996).

On the other hand, as Carless and Douglas (2013a) suggest, when, within the tale, some aspects emerge that do not fit the main narrative of performance, the narrator may justify them by resorting to patterns used within the dominant culture. In fact, Kartión's tale of flow pointed to a particular (perhaps peculiar) image he wants to portray about himself. Although his narrative lacked of some coherence, he justified it by constructing his achievements around the performance discourse. That is, by the way he told his story, he indicated the terms he wished to be understood (Riessman, 1993).

In addition, the flow experiences recounted by Kartión can be understood as stories about a sequence of events that are important to both the narrator and his audience (Denzin, 1989). In turn, this narrative configuration lends coherence and credibility to the recounted emotions, feelings, and facts to both parties. Therefore, Kartión's case confirms that a given narrative structure confers meaning to the narrated experiences (Smith \& Sparkes, 2009).

What is surprising here, however, is that, despite the apparently chaotic presentation of the flow experience narratives, this configuration is precisely what makes the story coherent and interesting. Had these been a simple succession of episodes, or a mere sequence of events, the narrative would have lost this additional dimension. Put in another way, what provides meaning to Kartión's story is, to a great extent, the apparent disorder in the plots, for it lends unity and intelligibility to the multiple and heterogeneous developments within it. In fact, one might argue that, without such narrative, these flow experiences would not exist for the interviewee, regardless of whether or not in the categorical-content analysis we, the researchers, could have identified certain dimensions of flow, as we will show in the next section.

\section{The narrative structure as a determinant factor of the flow experience}

The categorical-content analysis of the stories in this study show that the majority of the dimensions or factors defined for the construct of flow (Csikszentmihalyi, 1990) were present in Kartión's tale. The following interview fragment illustrates this point: 
(...) I did not realize what I was doing [loss of consciousness of one's self]. I simply knew that I was going to do it well. I do not know why. (...) I knew I was fine and was sure that I was going to perform well (...) [clear goals, and challengeability balance]. I was not thinking about what I was doing, but I knew what I was doing at all times [action-attention fusion, and feeling of control]. The experience seemed very short (...) [transformation of time]. (March 18, 2009)

Nevertheless, the stories in which our participant framed his flow experiences reveal something more beyond what up to now is seen in the research literature on this topic. For example, this literature defines flow experiences as "autotelic" moments, in which the person is fully immersed in their actions (Csikszentmihalyi, 1990). Yet, on occasion, this dimension of optimal experience did not acquire enough meaningful relevance for our participant to be identified as flow. For instance:

The training reflects the state you [sic] are in: how you are. You may say, "My God, it is impossible to run faster" (...). You're full of life, of strength, of (silence). This is what you enjoy. That is why I liked sports. I believe that human beings are born much like the animals, to run through Nature, through the woods, to enjoy the air they breathe. Say that you do that and do not get tired, fine; that you do get tired, but you can tolerate and overcome fatigue, fine also. Such is the pleasure of living: jumping, and enjoying (...). (March 18, 2009)

For this reason, the mere use of a content analysis that rests on the researcher's preconceived categorization may lead to an over-determination of the themes or categories identified in the data. Yet, certain moments that were inserted by Kartión into his biography (i.e., moments that, using traditional content analysis, could have been described as authentic autotelic experiences) were not taken as such by him. In other words, despite describing what could qualify as flow moments according to theory, Kartión, at times, did not consider them meaningful enough to be included in his tale. Rather, some narratives of flow analyzed in this study seem to be immersed in bigger autobiographical narratives that use resources and story-telling elements prevalent within the socio-cultural context in which they were produced.

In this sense, the results of this study support Douglas and Carless' (2009) arguments regarding the dominant role of performance narrative in elite sport. The results also back up Sparkes and Partington's (2003) remarks about the type of story that underlies flow narrative in some sporting sub-cultures: i.e., the heroic epic, which requires a heroic act (usually by a man) and avoids making references to the aesthetics of the surroundings. As such, Kartión selected flow experiences that constituted an important part of the traditional performance narratives.

From this, it follows that the performance narratives displayed by the participant restricted the very own content of the tale of flow experiences to the images through which he wanted to be seen. Moreover, his heroic tale clearly maintained Labov and Waletzky's (1967) epic structure, whereby the narrator, through his evaluation clauses (the soul of the narrative), pointed to how he wanted to be understood and his own perspective on flow. In this regard, Kartión discarded some traditional characteristics of an optimal experience (e.g., enjoying movement for its own sake) as worthy of being considered as flow.

In addition, by undertaking a structural analysis of the flow narrative, this study suggests that the very same structure of this type of narrative does confer portions of meaning. Thus, the Kartión's flow tale should not be considered a simple or transparent reflection of these experiences in an objective sense. Rather, he resorted to a mode of recounting (structuring) his experiences according to his own cultural context. As Sparkes (1999) emphasizes, any narrative, being a form of communication, is influenced by the socio-cultural conventions of the story, the motivations and actions of the narrator, the audience, and the social context. Similarly, Carless and Douglas (2013b) suggest that sportspersons, in general, "inhabit a culture awash with public stories relating to (preferred) identities, (expected) behaviors, and (assumed) 
developmental trajectories. These stories are widely circulated and amplified by the sport media" (p. 4). Certainly, within the context of the interviews, Kartión, as an elite sportsman, did appropriate these structures according to his dominant culture and conferred concrete meanings to his flow tale, which shows that narrative structure can actually construct, rather than reflect, the meaning of what is being told.

\section{Final comments and implications}

The flow experience narratives in this study can be understood as forms of speech that require content, structure, and a form of narration that shares socio-culturally established procedures and guidelines. Hence, the episodes of flow recounted by Kartión were inserted into larger autobiographical fragments, thereby providing a meaning mediated by (a) the structural forms that comprised the story in which the flow experiences were inserted, and (b) the sociocultural conventions that the narrator himself shared. This case indicates that the form and the content of the narrated flow experiences can be influenced by the structural substrate (i.e., a kind of narrative map that guides the informant as to what should be included or excluded when defining and narrating flow experiences) that provides these experiences with meaning of flow once inserted within the narratives associated to moments of peak athletic performance. Furthermore, certain episodes that, using a traditional categorical analysis, could have been categorized as flow experiences did not become major plots in the case of this athlete's tale.

This also points to the need to pay attention to the narrative structure of flow experiences, since it can provide not only additional understanding to what may be learned by simply focusing on referential meaning. For instance, it could shed some light on the narrative differences among groups and cultures (Jackson, 1992; Jones et al., 2000; Sparkes \& Smith, 2003). Therefore, future research delving deeper into the elements that have emerged here and focusing on other types of participants and contexts (e.g., female athletes, recreational settings) could yield revealing aspects about flow as well as the narrative structures and practices related to it. Moreover, the narrative analysis of flow could bring more clarity about a not-yet-settled debate regarding the definition and delimitation of peak moments in sport.

A narrative perspective suggests that the relation of flow with regard to peak performance and peak experience should be understood as a dynamic process that can vary depending on the narrator and the social and cultural context in which the narration of these types of experiences occurs. Hence, the key characteristics of peak performance usually appear when the person inserts flow narratives within a wider performance narrative, since, as the results of this study show, these narratives provide background meaning to flow in as much as they are associated with the sport successes of the protagonist.

On the other hand, the results corroborate that the distinctive characteristic of these narratives is a course of meaningful and coherent events, having a beginning, a mid-point, and an end. This is especially useful for the construction of flow theory in social psychology, since one of its main objectives is to unveil the complex dynamic relations that accompany people's experiences. Put differently, since the narrative construction of flow displays a dynamic order of such experiences, by analyzing flow from a narrative standpoint, social psychology researchers can begin to develop empirically-based and more comprehensive dynamic theories.

An important implication of this, for research on flow, stems from recognizing that the researcher's orientation or perspective will determine the nature of the construct under study (Gergen, 1994). For this reason, from a narrative analysis, the experiences of flow cannot be fully known simply by examining the participants' answers or comparing them to preestablished definitions. Doing so would obviate the fact that this type of narratives function not so much as to represent a particular reality; but, rather, in many cases, to convince the interviewer 
of the veracity of the story. This may explain why Kartión highlighted some experiences at the expense of others. Although these "truth claims" can be questioned, what needs to be foregrounded here is the fact that what gives meaning to a past event remembered as flow is not necessarily inherent to the experience itself, but, instead, to the particular context in which it is recalled.

Therefore, narrative research on flow could also have implications for further study in the field of sport psychology and social psychology. For example, the meanings Kartión has given to flow, while discarding other valuable meanings associated to peak experiences, have centered on peak sport performance, a dominant narrative in elite sports (Douglas \& Carless, 2009). In this line, Jackson and Csikszentmihalyi (1999) warn about focusing excessively on performance, since this could limit the harmonious balance of flow.

Flow is a harmonious experience where mind and body are working together effortlessly, leaving the person feeling that something special has just occurred. So flow is also about enjoyment. People associate flow with peak performance (...). Although winning is important, flow does not depend on it, and flow offers something more than just a successful outcome. (p. 5)

Finally, the main plot of Kartión's tale revolves around his achievement, victory, and development as sportsman, which assumes that this is the only way possible (Carless \& Douglas, 2013b). This type of discourse conforms, at least in part, to the construction of an exclusive and excluding athletic identity that, nonetheless, could have detrimental effects (Smith \& Sparkes, 2011; Sparkes \& Smith, 2003). Consequently, in order for people to be able to reconstruct their identities and their lives in positive ways, it may be appropriate to (a) foster and publicly share alternative narratives and (b) explain the role flow narratives play in the promotion or obstruction of sporting discourses and identity. This would help clarify the effects certain types of narratives have on people's sporting life and social relations. Doing so may serve well to those working in the sports context (e.g., athletes, coaches, sports psychologists, and social psychologists) for it would help them become aware of the importance of the tales people tell about optimal experiences in this field.

\section{References}

Carless, D., \& Douglas, K. (2009). "We haven't got a seat on the bus for you" or "All the seats are mine": Narratives and career transition in professional golf. Qualitative Research in Sport, Exercise $\mathcal{F}$ Health, 1(1), 51-66. http://dx.doi.org/10.1080/19398440 802567949

Carless, D., \& Douglas, K. (2013a). "In the boat" but "selling myself short": stories, narratives, and identity development in elite sport. The Sport Psychologist, 27(1), 27-39. http://dx.doi.org/10.1123/tsp.27.1.2 7

Carless, D., \& Douglas, K. (2013b). Living, resisting, and playing the part of athlete: Narrative tensions in elite sport. Psychology of Sport \&ु Exercise, 14(5), 701-708. http://dx.doi.org/10.1016/ j.psychsport.2013.05.003

Coffey, A., \& Atkinson, P. (1996). Making sense of qualitative data. London: Sage.

Csikszentmihalyi, M. (1975). Beyond boredom and anxiety. San Francisco: Jossey-Bass.

Csikszentmihalyi, M. (1990). Flow: The Psychology of Optimal Experience. New York: Harper \& Row.

Delle Fave, A. (2009). Optimal Experience and Meaning: Which Relationship. Psychological Topics, 18(2), 285-302. Retrieved from https://doaj.org/article/91bc 2256a6e245ccbc822469d0310a20

Delle Fave, A., \& Massimini, F. (1988). Modernization and the changing contexts of flow in work and leisure. In M. CsiKszentmihalyi \& I. S. Selega Csikszenmihalyi (Eds.), Optimal experience. Psychological studies of flow in consciousness (pp. 193-213). New York: Cambridge University Press. 
Denzin, N. K. (1989). Interpretive biography. Londres: Sage.

Douglas, K., \& Carless, D. (2009). Abandoning the performance narrative: Two women's stories of transition from professional sport. Journal of Applied Sport Psychology, 21(2), 213-230. Retrieved from http://eprints.leedsbeckett.ac.uk/335/ 7/Abandoning\%20The\%20Performance\% 20Narrative.pdf

Engeser, S. (Ed.). (2012). Advances in flow research. New York: Springer.

Gergen, K. (1994). Realities and relationships: soundings in social construction. Cambridge: Harvard University Press.

Jackson, S. A. (1992). Athletes in flow: A qualitative investigation of flow states in elite figure skaters. Journal of Applied Sport Psychology, 4(2), 161-180. http://dx.doi.org /10.1080/10413209208406459

Jackson, S. A., \& Csikszentmihalyi, M. (1999). Flow in sports. The keys to optimal experiences and performances: Human Kinetics.

Jackson, S. A., \& Marsh, H. W. (1996). Development and validation of a scale to measure optimal experience: The Flow State Scale. Journal of Sport and Exercise Psychology, 18, 17-35. Retrieved from https://pdfs.semanticscholar.org $/ 553 \mathrm{c}$ /9421dbb9d23735b0936e3743eaa021f0b4f 4.pdf

Jackson, S. A., Thomas, P. R., Marsh, H. W., \& Smethurst, C. J. (2001). Relationships between flow, self-concept, psychological skills, and performance. Journal of Applied Sport Psychology, 13(2), 129-153. http:/ dx.doi.org/10.1080/104132001753149865

Jones, C. D., Hollenhorst, S. J., Perna, F., \& Selin, S. (2000). Validation of the Flow Theory in an On-Site Whitewater Kayaking Setting. Journal of Leisure Research, 32(2), 247-261. Retrieved from https://www.cabdirect.org/c abdirect/abstract/20001812262

Labov, W., \& Waletzky, J. (1967). Narrative analysis: oral versions of personal experience. In J. Helm (Ed.), Essays on the verbal and visual arts (pp. 12-44). Seattle: University of Washington Press.

Landhäußer, A., \& Keller, J. (2012). Flow and its affective, cognitive, and performancerelated consequences. In S. Engeser (Ed.), Advances in flow research (pp. 65-85). New York: Springer.

Lieblich, A., Tuval-Mashiach, R., \& Zilber, T. (1998). Narrative research: Reading, analysis and interpretation. London: Sage.

Marsh, H. W., \& Jackson, S. A. (1999). Flow experience in sport: Construct validation of multidimensional hierarchical state and trait responses. Structural Equation Modeling, 6(4), 343-371. Retrieved from https://www.researchgate.net/publica tion/232515988_Flow_Experience_in_Spo rt_Construct_Validation_of_Multidimensi onal_Hierarchical_State_and_Trait_Resp onses

Maslow, A. H. (1968). Toward a psychology of being. New York: D. Van Nostrand Company.

McGannon, K., R., \& Mauws, M. K. (2000). Discursive psychology: An alternative approach for studying adherence to exercise and physical activity. Quest, 52 (2), 148-165. http://dx.doi.org/10.1080/003362 97.2000 .10491707

McInman, A. D., \& Grove, R. J. (1991). Peak moments in sport: A literature review. Quest, 43(3), 333-351. http://dx.doi.org/10 $.1080 / 00336297.1991 .10484035$

Mendoza, J. (2004). Las formas del recuerdo. La memoria narrativa [Electronic Version]. Athenea Digital, 6, Retrieved from http://w ww.redalyc.org/articulo.oa?id $=53700616$

Mitchell, R. (1988). Sociological implications of the flow experiences. In $M$. CsiKszentmihalyi \& I. S. Csikszenmihalyi (Eds.), Optimal experience. Psychological studies of flow in consciousness (pp. 36-59). New York: Cambridge University Press.

Polkinghorne, D. E. (1995). Narrative configuration in qualitative analysis. In A. Hatch \& R. Wisniewski (Eds.), Life History and Narrative (pp. 5-24). London: Falmer Press. 
Privette, G. (1983). Peak experience, peak performance, and flow: A comparative analysis of positive human experiences. Journal of Personnality and Social Psychology, 45(6), 1361-1368. Retrieved from http://psycnet.apa.org/index.cfm?fa = buy.optionToBuy\&id=1984-15068-001

Ravizza, K. (1984). Qualities of the peak experience in sport. In J. Silva \& R. Weinberg (Eds.), Psychological foundations of sport (pp. 452-461). Champaign: Human Kinetics.

Riessman, C. K. (1993). Narrative analysis. Newbury Park, Ca: Sage.

Riessman, C. K. (2008). Narrative methods for human sciences. Thousand Oaks, Ca: Sage.

Schüler, J., \& Brunner, S. (2009). The rewarding effect of flow experience on performance in a marathon race. Psychology of Sport $\mathbb{E}$ Exercise, 10(1), 168-174. https://doi.org/10 $.1016 /$ j.psychsport.2008.07.001

Smith, B., \& Sparkes, A. C. (2009). Narrative inquiry in sport and exercise psychology: What can it mean, and why might we do it? Psychology of Sport \& Exercise, 10(1), 1-11. http://dx.doi.org/10.1016/j.psychspor t.2008.01.004

Smith, B., \& Sparkes, A. C. (2011). Exploring multiple responses to a chaos narrative. Health, 15(1), 38-53. http://dx.doi.org/10.1 177/1363459309360782.

Sparkes, A. C., \& Partington, S. (2003). Narrative practice and its potential contribution to sport psychology: The example of flow. The Sport Psychologist, 17(3), 292-317. Retrieved from https://www.cabdirect.org/cabdirect/a bstract $/ 20033165697$ ?start $=4250$

Sparkes, A. C., \& Smith, B. (2003). Men, sport, spinal cord injury and narrative time Qualitative Research, 3(3), 295-320. Retrieved from http://journals.sagepub.com/doi/ abs/10.1177/1468794103033002

\section{Notes}

* Research article.

1 The italics within the quotes indicate the different elements of the narrative structure.

2 TN: El "Frente de Juventudes" was a governmental youth organization during Franco's time. 